\title{
The natural history of human immunodeficiency virus infection: a five year study in a London cohort of homosexual men
}

\author{
G E Kelly, B S Stanley, I V D Weller
}

\begin{abstract}
Progression rates from asymptomatic to symptomatic Human Immunodeficiency Virus (HIV) infection according to the CDC classification were prospectively studied in a cohort of 172 seropositive homosexual and bisexual men. The median follow-up time was 4 years. The progression from data of entry to the study to any group IV disease was $56 \%$ (SE $7 \%$ ) at 5 years. However, the progression from an estimated date of seroconversion to any group IV disease was $36 \%($ SE $4 \%$ ) at 5 years. This was more than double the progression rate to AIDS- $14 \%($ SE $3 \%)$ at 5 years calculated in the same way. There were no differences in progression to AIDS from group IV A (systemic symptoms such as unexplained fever, weight loss or persistent diarrhoea) and group IV C-2 (oral candida or oral hairy leukoplakia). Progression rates to AIDS were significantly lower $(p=0.02)$ in patients who were under 25 years of age at entry than in those over 25. A review of progression rates to AIDS among homosexual cohorts shows that they tend to be higher than in cohorts of haemophiliac patients, in the early stage of infection. However, when Pneumocystis carinii pneumonia is the outcome measure, progression rates in all studies are remarkably similar.
\end{abstract}

Certain aspects of the natural history of infection with the human immunodeficiency virus (HIV) have been extensively studied. Acturial progression rates to the acquired immunodeficiency syndrome (AIDS) following infection have been reported in many cohorts of homosexual and bisexual men..$^{1-7}$ AIDS,

Academic Department of Genito Urinary Medicine, University College and Middlesex School of Medicine, London UK

G E Kelly, B S Stanley, I V D Weller however, is the most extreme clinical endpoint of HIV infection. The Centers for Disease Control (CDC) classification system incorporates the broad spectrum of clinical manifestations of HIV infection. ${ }^{8}$ AIDS is often preceded by long-standing nonspecific constitutional symptoms such as unexplained weight loss, unexplained fever or diarrhoea (CDC group IV A) or other clinical signs such as oral hairy leukoplakia (OHL) and oral candida (CDC IV $\mathrm{C}-2$ ), producing significant morbidity and requiring close follow-up and treatment. It is therefore important to examine progression rates to all CDC group IV disease and only one study has attempted this. ${ }^{3}$

We have studied the natural history of HIV-I infection and we present progression rates to any group IV disease in a cohort of 172 homosexual men based in London. We also present progression rates from group IV A and IV C-2 to AIDS, and separately from OHL and oral candida to AIDS. We have compared our progression rates with those of other homosexual and haemophiliac cohort studies compiled from the literature.

\section{Patients and methods}

A total of 172 anti-HIV-I seropositive, asymptomatic homosexual and bisexual patients attending a London sexually transmitted disease clinic were recruited from November 1982 to form a cohort in which the natural course of HIV infection could be determined. Seventy of these were recruited as part of a study of generalised lymphadenopathy, which began in November 1982, before the anti-HIV test became routinely available in late 1984 . They were subsequently found to be anti-HIV antibody seropositive. All patients were followed through to August 1988 at regularly scheduled 3-month intervals. The CDC classification of 1986 for the manifestations of HIV infection was used to classify patients. ${ }^{8}$ The median date of entry to the cohort was December 1984. Progression rates from CDC groups II and III to all CDC IV sub-groups were computed.

In this study AIDS is defined as the following subgroups of CDC Group IV: subgroup IV B (specific neurological disease), subgroup IV C category C-1 (Pneumocystis carinii pneumonia (PCP) 
or specified secondary infectious diseases listed in the CDC classification), subgroup IV D (Kaposi's Sarcoma (KS) or lympyhoma) and subgroup IV E (other conditions). Progression rates to AIDS are computed for the cohort as a whole. Oral hairy leukoplakia (OHL) was introduced as part of group IV subgroup $\mathrm{C}$, category $\mathrm{C}-2$ at the beginning of $1986 .^{8}$ In this study, OHL varied from minimal to severe and in the majority of cases was not biopsy proven. Progression rates to AIDS separately from $\mathrm{OHL}$ and oral candida are also compared. Progression rates to PCP are examined separately for comparison purposes with other studies, in particular haemophiliacs for whom PCP is the most common AIDS outcome and in whom $\mathrm{KS}$ is unusual.

All progression curves were generated according to the Kaplan-Meier method using the Statistical Analysis Software (SAS). For each patient the date of first known HIV-seropositive result was the starting point on the follow-up scale. The exceptions to this were six patients for whom an HIV-seronegative date was available. For these six, the starting point was taken as the date midway between the last known negative and first known positive tests for anti-HIV. An alternative starting point for the follow-up will be discussed later as the above is almost certain to underestimate length of infection and thus overestimate cumulative progression rates over time.

In computing progression rates to any group IV illness all 172 patients were included in the risk set. The number of days of follow-up was taken to the date at which the patient developed a group IV disease or to the date of last visit at which the patient was asymptomatic before August 1, 1988. Progression rates to AIDS from group IV $A$, and from IV C-2 (oral candida or OHL) respectively, were computed in a similar manner.

Progression rates were also computed using an alternative starting point on the follow-up scale. From a study of HIV seropositivity in our clinic, the prevalence of HIV seropositivity in homosexual men was known to be $3.7 \%$ in March 1982 and $21 \%$ in July 1984 and has not changed significantly since then. ${ }^{910}$ Thus we assumed that the majority of homosexual men attending this STD clinic who acquired HIV infection did so between 1982 and 1984. Although 70 patients were recruited to this study because of generalised lymphodenopathy in November 1982, the majority of patients were recruited after this time. Therefore it seemed reasonable to use 15 May 1983, the median of the dates above, as an alternative starting point for follow-up for all patients. This date is an approximation for the median date of seroconversion of the cohort.

The log-rank test was used to test if age at entry to the study had prognostic value. It was also used to compared Kaplan-Meier progression curves. ${ }^{11}$ A $95 \%$ confidence interval was used for the difference in two sample proportions.

\section{Results}

PROGRESSION TO CDC GROUP IV FROM CDC GROUPS II

AND III

At study entry, $39(23 \%)$ of the cohort were in CDC group II and $133(77 \%)$ were in group III. Thirteen of 39 patients (33\% SE 8\%) progressed from group II to group IV disease and 48 of 133 patients (36\% SE $4 \%$ ) from group III to group IV disease, the difference being $3 \%$, which was not statistically significant. A 95\% confidence interval for the difference in progression from the two groups is $(-14 \%, 20 \%)$.

Table 1 Frequency of clinical diagnoses 1986

\begin{tabular}{|c|c|c|c|}
\hline Group & & Number & $\begin{array}{l}\text { Total with a diagnosis } \\
\text { in this group }\end{array}$ \\
\hline \multicolumn{4}{|c|}{$\begin{array}{l}\text { (A) First diagnosis by CDC classification } \\
\text { CDC IV A } \\
\text { Unexplained weight loss of over } 10^{\circ} \text {, or fevers, nightsweats } \\
\text { Or persistent diarrhoea }\end{array}$} \\
\hline $\begin{array}{l}\text { CDC IV C-2 } \\
\text { CDC IV B } \\
\text { CDC IV C-1 } \\
\text { CDC IV D }\end{array}$ & $\begin{array}{l}\text { Oral candida } \\
\text { Oral hairy leukoplakia } \\
\text { Specific neurological disease } \\
\text { PCP or other opportunistic infections } \\
\text { Kaposi's sarcoma or lymphoma }\end{array}$ & $\begin{array}{r}18 \\
20 \\
1 \\
4 \\
4\end{array}$ & \\
\hline CDC IV E & $\begin{array}{l}\text { Lymphoid interstitial pneumonitis (LIP) } \\
\text { Neurological disease and oral candida } \\
\text { PCP and oral candida }\end{array}$ & $\begin{array}{r}1 \\
1 \\
2 \\
61\end{array}$ & 13 \\
\hline $\begin{array}{l}\text { (B) First diagn } \\
\text { CDC IV B } \\
\text { CDC IV C-1 } \\
\text { CDC IV D } \\
\text { CDC IV E }\end{array}$ & ids & $\begin{array}{r}3 \\
14 \\
8 \\
1 \\
26\end{array}$ & $\begin{array}{r}7 \\
19 \\
10 \\
1\end{array}$ \\
\hline
\end{tabular}

LIP = lymphoid interstitial pneumonitis 


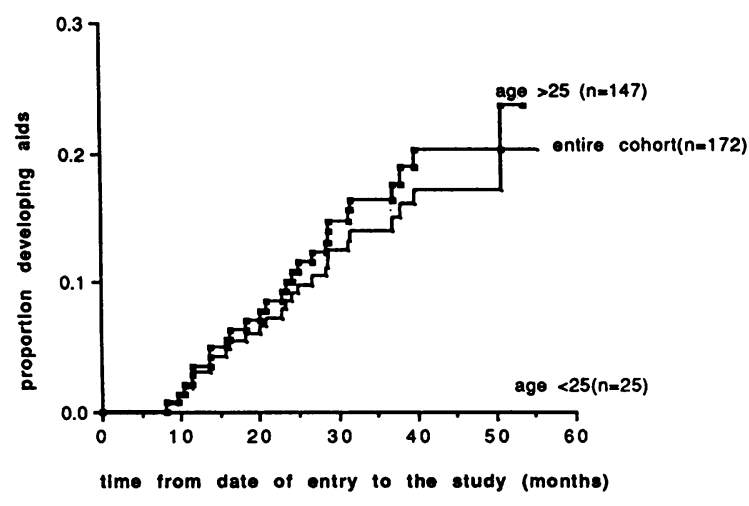

Figure Progression curves to aids in 172 seropositive men

In total 61 of the 172 seropositive men $(35.5 \%)$ progressed to group IV disease. Ten of the $61 \mathrm{had}$ CDC group IV $A$ as their first diagnosis, 38 had group IV C-2 (18 had oral candida, 20 had OHL) and 13 had an AIDS condition (table 1A). Of the 48 who did not have AIDS as the first diagnosis, 13 subsequently went on to develop AIDS. This gave a total of 26 of $172(15 \%)$ who developed AIDS in this cohort. In half of these cases AIDS was the first CDC group IV condition diagnosed (table 1B). Eight men were first diagnosed to have AIDS with KS (31\%), fourteen with PCP (54\%), three with neurological disease $(12 \%)$, and one with lymphoid intestinal pneumonitis (LIP). Some patients had multiple diagnoses (table 1A). The prevalence of neurological disease was seven out of twenty-six (27\%), of PCP 19 $(73 \%)$ and of $\mathrm{KS} 10(38 \%)$.
The progression rates to any group IV disease, to AIDS (fig) and to PCP were calculated using date of entry to the cohort and using May 15, 1983 as an estimated seroconversion date. The progression rates and the associated standard errors, together with the sample sizes on which the estimates are based are shown in table 2. The progression rate at 4 years to any group IV disease using date of entry to the cohort was $43 \%$, whereas using the estimated seroconversion date it was $21 \%$. This progression rate to Group IV disease of $21 \%$ is almost double the progression rate to $\operatorname{AIDS}(12 \%$ at 4 years).

PROGRESSION TO AIDS FROM ORAL CANDIDA, FROM OHL AND FROM ANY GROUP IV DISEASE Of the 61 patients progressing to group IV disease, 28 developed oral candida and 23 leukoplakia. However, 10 patients developed AIDS or another group IV disease before or simultaneously with oral candida and 3 patients developed AIDS or another group IV disease before $\mathrm{OHL}$. Thus in examining progression from oral candida and OHL to AIDS there were 18 and 20 respectively in the risk set (table 3 ). Seven patients with oral candida (39\%) progressed to AIDS. The median time to progression was 369 days almost 1 year exactly, that is, $50 \%$ of patients with oral candida are predicted to progress to AIDS within 1 year.

In 10 of the 20 patients with OHL, initial signs of OHL were minimal, in four they were overt and the remainder were not classified. In the 10 with minimal signs, five have progressed to having overt disease. In one patient symptoms disappeared, probably due to long term treatment with acyclovir. Four of the 20

Table 2 Cumulative progression rates (standard errors) from (a) date of entry to the cohort and from (b) known or estimated seroconversion date

\begin{tabular}{|c|c|c|c|c|c|c|}
\hline \multirow[b]{2}{*}{ Year } & \multicolumn{2}{|c|}{ No in follow-up } & \multicolumn{2}{|c|}{ Progression rate } & \multicolumn{2}{|c|}{ Standard error } \\
\hline & (a) & (b) & (a) & (b) & (a) & (b) \\
\hline $\begin{array}{c}\text { a) } \mathrm{An} \\
1 \\
2 \\
3 \\
4 \\
5 \\
\text { Num } \\
\text { Mean }\end{array}$ & $\begin{array}{r}V \text { dise } \\
156 \\
132 \\
81 \\
30 \\
8 \\
\text { nts wh } \\
\text { time: }\end{array}$ & $\begin{array}{r}(169) \\
(159) \\
(146) \\
(122) \\
(81) \\
\text { d: } 61 \text { or } \\
\text { S.E. } 0 \cdot 1\end{array}$ & $\begin{array}{r}7 \cdot 1 \% \\
15.7 \% \\
28.4 \% \\
42.9 \% \\
55.6 \%\end{array}$ & $\begin{array}{c}(0 \cdot 6 \%) \\
(5 \cdot 3 \%) \\
(11.9 \%) \\
(21.4 \%) \\
(35 \cdot 7 \%)\end{array}$ & $\begin{array}{l}2 \cdot 0 \% \\
2 \cdot 8 \% \\
3 \cdot 7 \% \\
4 \cdot 9 \% \\
7 \cdot 4 \%\end{array}$ & $\begin{array}{l}(0.6 \%) \\
(1.7 \%) \\
(2.5 \%) \\
(3.2 \%) \\
(3.9 \%)\end{array}$ \\
\hline $\begin{array}{c}\text { b) } \mathrm{Al} \\
1 \\
2 \\
3 \\
4 \\
5 \\
\text { Numb } \\
\text { Mean }\end{array}$ & $\begin{array}{r}163 \\
143 \\
93 \\
36 \\
9 \\
9 \\
\text { cts wl } \\
\text { time: }\end{array}$ & $\begin{array}{l}(169) \\
(165) \\
(153) \\
(135) \\
(102) \\
\text { ed: } 260 \\
\text { S.E. } 0.0\end{array}$ & $\begin{array}{r}3.0 \% \\
8.5 \% \\
14.0 \% \\
17 \cdot 1 \% \\
20 \cdot 2 \%\end{array}$ & $\begin{array}{c}(0.6 \%) \\
(1.8 \%) \\
(7 \cdot 2 \%) \\
(11.6 \%) \\
(14.3 \%)\end{array}$ & $\begin{array}{l}1 \cdot 3 \% \\
2 \cdot 2 \% \\
2 \cdot 8 \% \\
3 \cdot 2 \% \\
4 \cdot 3 \%\end{array}$ & $\begin{array}{l}(0.6 \%) \\
(1.0 \%) \\
(2.0 \%) \\
(2.5 \%) \\
(2.8 \%)\end{array}$ \\
\hline c) $\begin{array}{l}\mathrm{Pn} \\
1 \\
2 \\
3 \\
4 \\
5 \\
\text { Numt }\end{array}$ & $\begin{array}{c}\text { Carir } \\
164 \\
146 \\
96 \\
36 \\
9 \\
\text { cts wl }\end{array}$ & $\begin{array}{l}\text { ia } \\
(172) \\
(167) \\
(156) \\
(139) \\
(112) \\
\text { d: } 19 \text { ol }\end{array}$ & $\begin{array}{r}2 \cdot 4 \% \\
6 \cdot 1 \% \\
10 \cdot 1 \% \\
12 \cdot 4 \% \\
15 \cdot 6 \%\end{array}$ & $\begin{array}{c}(0.0 \%) \\
(0.6 \%) \\
(5.4 \%) \\
(9.2 \%) \\
(11.9 \%)\end{array}$ & $\begin{array}{l}1 \cdot 2 \% \\
1.9 \% \\
2 \cdot 4 \% \\
2 \cdot 8 \% \\
4 \cdot 2 \%\end{array}$ & $\begin{array}{l}(0.0 \%) \\
(0.6 \%) \\
(1.8 \%) \\
(2.3 \%) \\
(2.6 \%)\end{array}$ \\
\hline
\end{tabular}


Table 3 Cumulative progression rates from subgroups of CDC group IV to aids

\begin{tabular}{llll}
\hline Diagnosis & Number with diagnosis & Mean follow-up time, years (S.E.) & Progression rate (S.E.) 1 yr \\
\hline IV C-2 ORAL CANDIDA & 18 & $0.79(0.09)$ & $51 \cdot 1 \%(13.9 \%)$ \\
ORAL HAIRY LEUKOPLAKIA & 20 & $0.92(0.06)$ & $41.2 \%(16.5 \%)$ \\
GROUPS IV A AND IV C-2 & 48 & $0.95(0.06)$ & $42.8 \%(10.0 \%)$ \\
\hline
\end{tabular}

leukoplakia patients progressed to AIDS (20\%). The cumulative progression rate to AIDS at 1 year was $41 \%$, not significantly different compared with that for oral candida.

Combining groups CDC IV A and IV C-2 (oral candida and OHL), giving a risk set of 48 , the progression rate to AIDS at one year was $43 \%$ (SE 10\%).

\section{AGE}

The median age at entry to the cohort was 32 years ranging from 20 to 55 . Age at date of entry to the study was significantly associated with both progression to either any group IV disease $(p=0.04)$ and progression to AIDS ( $p=0.02$ ) by the log-rank test (fig). At entry only seven patients were aged less than 21 years. Twenty eight, however, were aged less than 25 and none progressed to AIDS after a median follow-up of three years. For those aged over 25, the progression rate at 3 years was $16 \cdot 5 \%$. The KaplanMeier progression curves for these two age groups are significantly different $(p=0.02)$.

\section{Discussion}

Our finding that patients in group III had no increased risk of developing symptomatic disease over those in group II agrees with other studies in the literature. ${ }^{312} 13$

Few studies report progression rates to any group IV disease. The San Francisco General Hospital . cohort study in 288 seropositive homosexual men reported a $41 \%$ progression rate from estimated seroconversion date to any group IV disease at six years, compared with $36 \%$ (SE $4 \%$ ) at five years for this study. ${ }^{3}$ This is more than double the progression rate to AIDS. Their estimate of a $44 \%$ progression rate from ARC to AIDS at two years also agrees with our estimates of $40 \%$ (SE $10 \%$ ) at one year from CDC IV A and IV C-2 combined. There were no differences in our one year progression rates to AIDS, from CDC group IV A oral candida and OHL respectively. This is an important finding in that oral candida in clinical practice is perhaps taken as an important indication for early intervention with zidovudine, whereas OHL is not. The progression rate from oral candida to AIDS of $43 \%$ at one year (SE 14\%) is in agreement with the study of Klein who found that of 22 patients with oral candida, 13 (59\%) developed AIDS at a median of three months. ${ }^{14}$ Survival analysis has been used in another study to compute progression rates from OHL to AIDS (48\% at 16 months and $83 \%$ at 31 months). ${ }^{15}$ Our estimated progression rate of 37\% (SE 16\%) at one year supports these findings. It is clear, however, that larger sample sizes are needed in order to estimate these rates more precisely.

Progression rates to AIDS in cohorts of homosexual and bisexual men reported in the literature have varied widely. In one study the three year cumulative incidence rate of AIDS was $34 \%$ for men in New York city, $17 \%$ for men in Washington DC and $8 \%$ for men in Denmark. ${ }^{1}$ It has been suggested that these differences occurred because some cohorts had been infected longer than others, and it is well known that the risk of AIDS for HIV infected persons increases over time. ${ }^{16-18}$ Therefore, in comparing the progression rates to AIDS, of the present study with others, we have restricted attention to those where the date of seroconversion is either known or estimated. The results of six such independent studies are shown in table 4. ${ }^{24.19}$ Unfortu-

Table 4 Cumulative progression rates (\%) to AIDS from known (K) or estimated $(E)$ date of seroconversion in studies of homosexual men and haemophiliacs

\begin{tabular}{|c|c|c|c|c|c|c|c|c|c|c|}
\hline & & 1 & 2 & 3 & 4 & 5 & 6 & 7 & 8 & 9 \\
\hline \multicolumn{11}{|c|}{ Studies in homosexual men } \\
\hline \multirow{3}{*}{$\begin{array}{l}\text { Biggar: et al } \\
\text { Hessol: et al } \\
\text { Moss: et al } \\
\text { Munoz: et al } \\
\text { Phair: etal } \\
\text { Schecter: et al }\end{array}$} & \multirow{3}{*}{$\begin{array}{l}\text { International }(K)(n=476) \\
\text { SF City Clinic }(K)(n=181) \\
\text { SF General Hospital }(E)(n=288) \\
\text { MACS: all subjects }(E)(n=1523) \\
\text { MACS Seroconvertors }(K)(n=277) \\
\text { Vancouver }(K)(n=96) \\
\text { Present Study }(\mathrm{E})(n=172)\end{array}$} & 0.4 & $3 \cdot 1$ & $\begin{array}{l}6 \cdot 6 \\
4 \cdot 0\end{array}$ & $\begin{array}{r}11.5 \\
9.0 \\
5.0\end{array}$ & $\begin{array}{l}22 \cdot 8 \\
14 \cdot 0 \\
11.0\end{array}$ & \multirow[t]{3}{*}{$\begin{array}{l}36 \cdot 4 \\
22 \cdot 0 \\
22 \cdot 0\end{array}$} & \multirow[t]{3}{*}{$34 \cdot 0$} & \multirow[t]{3}{*}{$38 \cdot 0$} & \multirow[t]{3}{*}{$42 \cdot 0$} \\
\hline & & 0.5 & $4 \cdot 0$ & $\begin{array}{r}11 \cdot 2 \\
8 \cdot 0\end{array}$ & $15 \cdot 8$ & $20 \cdot 5$ & & & & \\
\hline & & 0.6 & $1 \cdot 8$ & $7 \cdot 2$ & $11 \cdot 6$ & $\begin{array}{l}13 \cdot 0 \\
14 \cdot 3\end{array}$ & & & & \\
\hline \multicolumn{11}{|c|}{ Studies in haemophiliacs } \\
\hline $\begin{array}{l}\text { Biggar: et al } \\
\text { Giesecke: et al }\end{array}$ & $\begin{array}{l}\text { International Adults }(\mathrm{K})(\mathrm{n}=173) \\
\text { Sweden }(\mathrm{K})(\mathrm{n}=98)\end{array}$ & $\begin{array}{l}0 \\
0\end{array}$ & $\begin{array}{l}0 \cdot 6 \\
0\end{array}$ & $\begin{array}{l}4 \cdot 2 \\
0\end{array}$ & $\begin{array}{r}10 \cdot 9 \\
1.0\end{array}$ & $\begin{array}{r}15 \cdot 8 \\
5 \cdot 0\end{array}$ & 23.9 & & & \\
\hline $\begin{array}{l}\text { Goedert: et al } \\
\text { Lee: et al }\end{array}$ & $\begin{array}{l}\text { Maryland, U.S. Aduilts }(K)(n=304) \\
\text { London }(K)(n=104)\end{array}$ & 0 & 0.3 & $2 \cdot 3$ & $5 \cdot 3$ & $10 \cdot 3$ & $15 \cdot 3$ & $19 \cdot 3$ & $\begin{array}{l}29 \cdot 3 \\
31 \cdot 0\end{array}$ & $39 \cdot 3$ \\
\hline
\end{tabular}


Table 5 Cumulative progression rates (\%) to PCP from known or estimated seroconversion date

\begin{tabular}{|c|c|c|c|c|c|c|c|}
\hline \multirow[b]{2}{*}{ Study } & & \multicolumn{6}{|c|}{ Year } \\
\hline & & 1 & 2 & 3 & 4 & 5 & 6 \\
\hline $\begin{array}{l}\text { Biggar et al: } \\
\text { Eyster et al: }\end{array}$ & $\begin{array}{l}\text { Adult }(\mathrm{K}) \text { Haemophiliacs }(\mathrm{n}=173) \\
\text { Homosexuals }(\mathrm{K})(\mathrm{n}=476) \\
\text { Haemophiliacs }(\mathrm{K})(\mathrm{n}=\mathbf{8 4}) \\
\text { Present Study }(\mathrm{E})(\mathrm{n}=172)\end{array}$ & $\begin{array}{l}0 \\
0 \cdot 2 \\
0 \\
0\end{array}$ & $\begin{array}{l}0.6 \\
1 \cdot 4 \\
0 \\
0.6\end{array}$ & $\begin{array}{l}3 \cdot 0 \\
3 \cdot 3 \\
3 \cdot 0 \\
5 \cdot 4\end{array}$ & $\begin{array}{l}8 \cdot 5 \\
7 \cdot 1 \\
9 \cdot 0 \\
9 \cdot 2\end{array}$ & $\begin{array}{l}10 \cdot 3 \\
12 \cdot 1 \\
11 \cdot 0 \\
11.9\end{array}$ & $\begin{array}{l}17 \cdot 5 \\
18 \cdot 3 \\
18 \cdot 0\end{array}$ \\
\hline
\end{tabular}

nately, most studies have not reported standard errors along with progression rates. The estimated cumulative rates at 5 years ranged from $11 \%$ to $23 \%$ with a median of $14 \%$. The corresponding estimate in this study is also $14 \%$ (SE 3\%) showing excellent agreement. But, it is clear that there is still some variability across studies even when date of seroconversion has been controlled for.

There has been much discussion in the literature concerning the hypothesis that haemophiliac patients have a lower incidence of AIDS than do homosexual men. ${ }^{120} \mathrm{We}$ have reproduced progression rates from AIDS from studies of haemophiliacs with known or estimated date of seroconversion ${ }^{61-23}$ (table 4). It is clear that progression rates again vary, ranging from $5.0 \%$ to $16.0 \%$ at five years.

The compiled studies also showed slightly lower progression rates among haemophiliacs than in homosexual men. This may be due to the higher incidence of KS in the latter which is rarely seen in haemophiliac patients. ${ }^{13}$ Because of this, and since diagnosis with $\mathrm{PCP}$ has a poorer prognosis than $\mathrm{KS}$, progression rates to PCP provide us with a more equitable comparison of homosexual and haemophiliac cohorts. ${ }^{24} 25$ Results of studies reporting Kaplan-Meier progression rates to PCP are shown in table 5 along with the results of the present study. ${ }^{613}$ The results from all studies are remarkably similar, being $11.5 \%$ at five years and $18.0 \%$ at six years. In addition the study in US haemophiliacs with the longest follow-up, reported a $39.0 \%$ progression rate to AIDS at nine years almost identical to the San Francisco City Clinic rate of 42.0 at nine years for homosexual men. Similarly a study of 1445 German haemophiliacs, estimated a $50 \%$ progression rate to AIDS at nine years. ${ }^{26}$ This evidence suggests that the long term progression rates to AIDS for haemophiliac and homosexual cohorts are the same.

Four studies listed in tables 4 and 5 also showed age as a cofactor for progression..$^{361322}$ In the San Francisco General Hospital cohort the difference was between the under 35 year olds versus over $35 \mathrm{~s}$ $(\mathrm{p}=0.02) .{ }^{3}$ Among haemophiliacs in the seroconverters working group study it was for under 21 years versus over $21(p=0.003)$ and for Eyster's study again it was for under 21 versus over $21(p=0.03)$. The study by Goedert of US haemophiliacs also showed marked differences between annual AIDS rates among haemophiliacs less than 21 years old versus those greater than 21 years old. ${ }^{22}$ The former had a cumulative incidence of AIDS at $19 \%$ at 8 years, while for the latter it was $29 \%$ at 8 years. Our study agrees with those of Eyster, Goedert and the seroconverters study in that we found a significant difference between under and over 25 year olds $(p=0.02)$. As only seven of the cohort were aged less than 21,21 years could not be used as a cut-off for comparison. The difference in progression rates between under and over 35 year olds was not significant in this study.

We have considered it important to examine progression rates to all CDC groups for the following reasons. Firstly, with the introduction of antiviral drugs in the assessment of treatment of patients in CDC groups II and III efficacy is being determined by the delay in onset of any group IV disease. ${ }^{27}$ Secondly it is important to establish what the differences are, if any, in progression rates from the different CDC groups and subgroups to later disease. Thirdly, different diagnoses involve different treatment and use of resources. By assessing the frequency of each type of clinical diagnosis and its duration, the cost of care may be more effectively assessed and resources planned.

All the evidence suggests that the natural history of this cohort is similar to those of other cohorts of homosexual men reported in the literature. This being the case, the long term prognosis is poor. The San Francisco City Clinic cohort progression rate of $42 \%$ at nine years is likely to repeat itself here. ${ }^{2}$ The evidence also suggests that almost all of the patients in this cohort will have progressed to some stage IV disease by that time. The magnitude of the progression rates, however, make the current movement for the assessment of therapeutic intervention before stage IV disease, that is, in asymptomatic patients, very compelling. ${ }^{27}$

This study was supported by the Medical Research Council, the Wellcome Trust and the Frances and Augustus Newman Foundation. The authors thank colleagues in the Virology Section of the Department of Medical Microbiology for serum storage and antiHIV testing on the cohort.

Requests for reprints to: Dr G E Kelly, James Pringle House, 73-75 Charlotte Street, London W1N 8AA, UK 


\section{References}

1 Goedert JJ, Biggar RJ, Weiss SH et al. Three-year incidence of AIDS in five cohorts of HTLV-III-infected risk group members. Science 1986;231:992-5.

2 Hessol NA, Rutherford GW, Lifson AR, et al. The natural history of HIV infection in a cohort of homosexual and bisexual men: a decade of follow-up. IV International Conference on AIDS, Stockholm, June 1988. (Abstract 4096).

3 Moss AR, Bacchetti P, Osmond D et al. Seropositivity for HIV and the development of AIDS or AIDS related condition: 3 year follow-up of the San Francisco General Hospital Cohort. Br Med J 1988;296;744-50.

4 Phair J, Munoz A, Kingsley L et al. Incidence of AIDS in Homosexual Men Developing HIV Infection. IV International Conference on AIDS, Stockholm, June 1988. (Abstract 4093).

5 Schecter MT, Craib KJ, Willoughly B, et al. Progression to AIDS in a Cohort of Homosexual Men: Results at 5 Years. IV International Conference on AIDS, Stockholm, June 1988. (Abstract 4098).

6 Biggar RJ. Time-to-AIDS among 816 seroconvertors: Seroconvertors Working Group. V International Conference on AIDS, Montreal, Canada, June 1989. (Abstract Th.A.O.22).

7 Moss AR, Bacchetti P. Natural history of HIV infection. AIDS 1989;3:55-61.

8 Centers for Disease Control, U.S. Department of Health and Human Services, Atlanta, Georgia. Classification System for Human T-Lymphotrophic Virus Type III/Lymphadenopathy-Associated Virus Infections. Ann Intern Med 1986;105:234-7. Also MMWR 1986;35:334-9.

9 Carne C, Weller I, Johnson A et al. Prevalence of antibodies to human immunodeficiency virus, gonorrhoea rates, and changed sexual behaviour in homosexual men in London. Lancet 1987;i:656-8.

10 Loveday C, Pomeroy L, Weller IVD, et al. Human immunodeficiency viruses in patients attending a sexually transmitted disease clinic in London, 1982-7. Br Med J 1989;298:419-22.

11 Miller R. (1981). Survival Analysis. New York: Wiley.

12 Polk BF, Fox R, Brookmeyer R, et al. Predictors of the acquired immunodeficiency syndrome developing in a cohort of seropositive homosexual men. N Engl J Med 1987;316:61-6.

13 Eyster M, Gail M, Ballard J, et al. Natural history of human immunodeficiency virus infections in haemophiliacs. Ann Intern Med 1987;107:1-6.

14 Klein RS, Harris CA, Small CB et al. Oral candidasis in high risk-patients as the initial manifestation of the acquired immunodeficiency syndrome. N Engl J Med 1984;311:354-8.

15 Greenspan D, Greenspan JS, Hearst JG, et al. Relation of oral hairy leukoplakia to infection with the human immunodeficiency virus and the risk of developing AIDS. $J$ Infect Dis 1987;155:475-81.

16 Lifson AR, Rutherford GW, Jaffe HW. The natural history of human immunodeficiency virus infection. $J$ Infect Dis 1988; 158:1360-7.

17 Kaplan AR, Spira TJI, Fishbern DB, Bozeman LH, Pinsky PF, Schonberger LB. Evidence for an increased risk in developing AIDS after the third year of lymphadenopathy. JAMA 1988; 260:2694-7.

18 Rezza G, Lazzarini A, Angarano G, et al. The natural history of HIV infection in intravenous drug users. AIDS 1989;3:87-90.

19 Munoz A, Wang MC, Good S, et al. Estimation of the AIDSfree times after HIV-1 seroconversion. IV International Conference on AIDS, Stockholm, June 1988. (Abstract 4129).

20 Jason J, Lui KJ, Ragni M, Hessol NA, Darrow WW. Risk of developing AIDS in HIV-infected cohorts of haemophiliac and homosexual men. JAMA 1989;261:725-7.

21 Giesecke J, Scalia-Tomba G, Beergland O, Berntorp E, Schulman S, Stigendal L. Progression to AIDS in haemophiliacs and blood transfusion recepients infected with human immunodeficiency virus. Br Med J 1988;297:99-102.

22 Goedert JJ, Eyster NE, Friedman RN, Gail MH. AIDS rates, markers and cofactors. IV International Conference on AIDS. Stockholm, June 1988. (Abstract 4144).

23 Lee CA, Miller EJ, Griffiths PD, Janossy G, Kernoff PB. HIV disease in a cohort of 104 haemophiliacs. IV International Conference on AIDS, Stockholm, June 1988 (Abstract 7733).

24 Marasca F, McEvoy M. Length of survival of patients with acquired immunodeficiency syndrome in the United Kingdom. Br Med J 1986;292:1727-9.

25 Rothenberg R, Woelfel M, Stoneburner R, Milbert J, Parker R, Truman $B$. Survival with the acquired immunodeficiency syndrome. N Engl J Med 1987;317:1297-1302.

26 Frosner G. Estimation of mean incubation time of HIV infection as derived from data of German haemophiliacs. IV International Conference on AIDS, Stockholm, June 1988. (Abstract 7832).

27 Gelmon K, Weller I. Randomised placebo controlled trials in HIV infection: to be or not to be? Genitourin Medicine 1989;65:143-5.

Accepted for publication 3 January 1990 